\title{
Eficácia da gastronomia na aceitabilidade da alimentação escolar
}

Virgínia Souza Santos, Diana Elen da Silva, Monise Viana Abranches, Giovanna Gaudenci Nardelli, Eliana Maria Gaudenci, Leila Aparecida Kauchakje Pedrosa

\section{Resumo}

O uso de técnicas gastronômicas pode ser uma alternativa eficaz para a melhoria da aceitação da alimentação escolar, especialmente na fase pré-escolar, quando as crianças sentem a necessidade de tocar a comida, sentir as formas, texturas e aromas, além de poderem descobrir as diferentes cores dos alimentos. Avaliar a aceitação da alimentação escolar antes e após o emprego de técnicas gastronômicas, por crianças em idade pré-escolar. Participaram da pesquisa 26 crianças, com idade mediana de 5,4 anos $(5,0$ - 5,9), sendo 53,8\% (n=14) do sexo feminino, cujos pais autorizaram a participação mediante a assinatura do Termo de Consentimento Livre e Esclarecido. Para avaliação da aceitabilidade da alimentação escolar, foi aplicado um teste afetivo, empregando-se a escala hedônica facial de 5 pontos, durante 5 dias consecutivos e no mesmo horário, conforme proposto pelo Centro Colaborador de Alimentação e Nutrição Escolar - CECANE (2010). As refeições que apresentaram o Índice de Aceitabilidade (I.A.) $\geq 85 \%$ (percentual referente ao somatório das notas 4 e 5 atribuídas pelos alunos no teste afetivo) foram consideradas aceitas. Na fase seguinte, com a mesma duração, foram executadas modificações na alimentação escolar, empregando técnicas gastronômicas que permitissem uma melhor apresentação dos pratos servidos as crianças, por meio da utilização de aros de formatação de alimentos para enfeitar os pratos e o uso de condimentos para dar coloração e decorar os alimentos. Novamente foi realizada a analise sensorial das refeições distribuídas. Para a análise dos dados foi utilizado software Statistic Package for the Social Sciences - SPSS, versão 20.0 e empregou-se o teste Wilcoxon para comparação da média da pontuação atribuída pelos voluntários antes e após a aplicação das técnicas gastronômicas. $\mathrm{O}$ estudo foi aprovado pelo Comitê de Ética em Pesquisa da Universidade Federal de Viçosa (protocolo no 773.222). De acordo com a análise sensorial, observou-se que a pontuação atribuída as refeições aumentou após o emprego da gastronomia, durante todos os dias. Foi observada diferença estatística apenas nas quartas-feiras ao comparar as notas atribuída antes e depois da aplicação das técnicas gastronômicas. Após a intervenção, houve aumento do índice de aceitação e todas as refeições passaram a ser aceitas (I.A. > 85,0\%). As notas atribuídas pelos estudantes, mediante a aplicação do teste de aceitabilidade, aumentaram após o emprego de técnicas gastronômicas, o que permite inferir que essa estratégia possibilitou a melhoria da aceitabilidade da alimentação escolar.

Descritores: Gastronomia; Alimentação escolar; Análise sensorial. 